\title{
La adopción de una innovación agraria en España: los orígenes del cultivo de la remolacha azucarera. Experiencias pioneras y su repercusión económica y territorial
}

\section{The adoption of an agricultural innovation in Spain: the origins of the farming of sugar beet. Pioneering experiences and its economic and territorial impact}

\author{
María Jesús Marrón Gaite*
}

\section{INTRODUCCIÓN}

Hasta el inicio del siglo XIX no existía en el mundo otro azúcar que el elaborado a partir de la caña. Los conflictos coloniales y los problemas que de ellos se derivaron para abastecer los mercados europeos de diversos productos, entre ellos el azúcar, que constituía un alimento generalizado, desencadenaron una intensa investigación en diversos países europeos para encontrar un sustituto de la caña como materia prima para la obtención de este preciado alimento. Fue en 1799 cuando, con el apoyo de Federico el Grande de Prusia, Andreas Marggraf descubrió que la Beta vulgaris contiene sacarosa en su raíz, al tiempo que inventó un procedimiento industrial para obtener azúcar a partir de ella, ofreciendo al rey la primera muestra de este producto. Su labor fue culminada por su discípulo Franz Carl Achard, que en 1802 creó en Güner

* Departamento de Didáctica de las Ciencias Sociales, Universidad Complutense de Madrid. España (mjmarron@edu.ucm.es). 
(Silesia) la primera fábrica de azúcar de remolacha del mundo. Esta experiencia innovadora se difundió rápidamente por Francia, Bélgica, Austria, Rusia, Italia y otros países europeos, impulsada siempre por los fabricantes de azúcar y por la acción gubernamental.

En España habrá que esperar setenta y dos años para que esta innovación se empiece a experimentar; sobre todo, porque España disponía del azúcar procedente de sus colonias antillanas, especialmente de Cuba. En 1874, tras el conocimiento de los excelentes resultados que la industria azucarera estaba obteniendo en gran parte de los países europeos y los enormes beneficios económicos que generaba, se inician los primeros ensayos para la adopción del cultivo de la remolacha azucarera, los cuales tuvieron un carácter puramente experimental. No será hasta 1882-1883 cuando, tras diversas pruebas y experiencias agronómicas, se realice la primera campaña remolachera y se obtenga la remolacha suficiente para lanzar a los introductores del nuevo cultivo a la creación de las dos primeras fábricas de azúcar de remolacha de nuestro país.

Tanto los ensayos sobre este cultivo novedoso como la instalación de estas primeras fábricas se llevaron a efecto en dos ámbitos del campo andaluz por la iniciativa personal de Ricardo Martel y Fernández de Córdoba, Conde de Torres-Cabrera, y Juan López-Rubio Pérez. Ambos, de forma simultánea e independiente, introdujeron el cultivo con semillas francesas en Alcolea (Córdoba) y en Cúllar-Vega (Granada), respectivamente, e instalaron en sendas localidades las citadas fábricas de azúcar. Eran hombres próceres y ricos terratenientes andaluces ${ }^{1}$ que conocían muy bien la experiencia europea en la fabricación de azúcar de remolacha y en el cultivo de esta planta, así como los altos beneficios que esta industria estaba generando en países como Alemania, Francia e Italia. El objetivo que perseguía cada uno de ellos era la instauración en nuestro país de este sistema de fabricación, para lo cual el paso previo era contar con la materia prima para mover las fábricas². Tanto López-Rubio como Torres-Cabrera conocían el déficit azucarero del país en ese momento y cómo las relaciones con nuestras colonias abastecedoras eran cada día más tensas. Así mismo, sabían que desde la reforma arancelaria de 1868 este déficit se venía cubriendo con

1 Torres-Cabrera era Senador del Reino y Gobernador Civil de Córdoba. López-Rubio era farmacéutico y estaba casado con una hija de los Pérez Acosta, una de las familias más ricas de Granada. Ambos poseían en sus respectivas provincias un importante patrimonio en terrenos agrarios.

2 En España hasta 1882 el único azúcar producido era el de caña. Los ingenios azucareros empleaban para su elaboración grandes cantidades de caña antillana, a la que se unía la producida en el país, que era claramente insuficiente. 
cantidades cada vez mayores de azúcar procedente de países europeos, especialmente de Francia y Alemania, que contaban con una potente industria de fabricación de azúcar a partir de la remolacha. Todo ello les inducía a pensar que la fabricación de azúcar en España por el mismo sistema constituiría un magnífico negocio. Para la consecución de este objetivo contaban además con un doble estímulo; por una parte, el prestigio social que suponía ser el primer fabricante de azúcar de remolacha en España; por otra, los beneficios que se derivarían de un negocio que podía acogerse a los privilegios de patente en exclusiva del producto. Téngase en cuenta que en toda Europa la fabricación de azúcar se hacía bajo el sistema monopolístico, razón por la cual estos dos pioneros consideraron que también en España se haría así. En función de estas consideraciones, una vez que cada uno de los dos conoció los ensayos que sobre el cultivo estaba realizando el otro, el afán por ser el primero en conseguir la patente de fabricación lanzó a Torres-Cabrera y a López-Rubio a una vertiginosa carrera para implantar el cultivo de la remolacha azucarera en tierras cordobesas y granadinas respectivamente. Ambos alcanzaron los resultados apetecidos y sus experiencias sentaron las bases de un cultivo que se difundió de forma rapidísima, casi vertiginosa, por el territorio nacional, de la mano de la industria azucarera.

La coyuntura político-económica del país a finales del xIX e inicios del xx favoreció ese carácter rápido e intenso de la expansión del cultivo, la cual fue arbitraria y caótica hasta mediados de los años treinta del siglo xx, llegando a provocar serias tensiones en el sector y problemas de saturación en el mercado del azúcar. Ante ello, la Administración promulgó en 1935 la Ley del Azúcar, primera de las que se han sucedido hasta nuestros días. A través de ella se llevó a cabo la reglamentación y planificación del sector, regulando el Gobierno la producción de azúcar y de las materias primas destinadas a su obtención, al tiempo que se fijó el cultivo de la remolacha a unas áreas territoriales concretas, que acabarían tipificándose como «zonas remolacheras». A partir de ese momento el cultivo de la remolacha creció de forma ordenada y progresiva a nivel nacional, llegando a ser uno de los cultivos más destacados en nuestro país. Alcanzó su máxima expansión en la década de los años setenta y hasta mediados de los ochenta del pasado siglo, periodo en el que llegó a ocupar en varios años más de 250.000 ha, apoyado siempre por una estricta reglamentación.

Sin embargo, este cultivo, que tanta importancia ha tenido en nuestro país tanto económicamente como desde el punto de vista social, pues sus cultivadores son mayoritariamente agricultores con pequeñas explotaciones, se ha visto negativamente afectado desde finales de los años ochenta del pasado siglo, debido al establecimiento de los cupos de producción de azúcar realizado por la PAC (Política Agraria Comunitaria) para los países de la Unión Euro- 
pea. La consecuencia inmediata ha sido una intensa y progresiva caída del cultivo a partir de ese momento, situándose en 1999 en 137.100 ha cultivadas, casi la mitad de las tierras ocupadas en las dos décadas anteriores. La situación se ha agravado aún más desde la Reforma Intermedia de la PAC de 2002/2003 y la reducción del cupo de producción de azúcar de nuestro país a la mitad del cupo anterior. Esta última reforma ha supuesto una auténtica puntilla para el cultivo de la remolacha azucarera en España que, según los últimos datos publicados en el Anuario de Estadística del Ministerio de Medio Ambiente y Medio Rural y Marino, ocupaba en 2008 una superficie de 52.295 ha. Pero todo ello será objeto de otro estudio posterior, volvamos ahora al momento inicial.

Las dos experiencias pioneras fueron decisivas para la introducción del cultivo remolachero en España y para su posterior difusión por el territorio nacional; sin embargo, la influencia que cada una de ellas tuvo en el ámbito local y comarcal donde se realizaron fue completamente distinta. La realizada por López-Rubio tuvo una enorme repercusión en amplias zonas de regadío de la provincia de Granada. A partir de ella el nuevo cultivo se difundió por las vegas de Granada, Guadix y Baza, de donde saltó ya en los primeros momentos a las provincias de Almería y Málaga, produciendo una auténtica revolución agraria y económica en todas las áreas donde el cultivo se fue adoptando, con las transformaciones territoriales y paisajísticas que de ello se derivaron.

Por el contrario, la iniciativa innovadora de Torres-Cabrera constituyó una experiencia aislada en el campo cordobés, que no fue secundada por sus convecinos debido a múltiples causas concurrentes, entre las que destacan la falta de tradición azucarera en Córdoba - en Granada existía una larga tradición azucarera basada en el empleo de la caña de azúcar como materia prima y se tenía la idea de que toda actividad relacionada con el azúcar era económicamente rentable- y la propia concepción paternalista que Torres-Cabrera tenía de la empresa agraria, que en nada estimulaba la iniciativa personal de los agricultores. Sin embargo, a Torres-Cabrera le cabe el honor de haber sido el creador de la primera fábrica de azúcar de remolacha y quien por primera vez obtuvo en España azúcar a partir de ella, una muestra de la cual ofreció al rey Alfonso XIII como primicia de este nuevo producto. El conocimiento de la existencia de esta fábrica por parte de empresarios y hombres de negocios del momento desencadenó una auténtica fiebre azucarero-remolachera en España, las fábricas de azúcar de remolacha surgieron por todo el territorio nacional y de la mano de ellas el cultivo se difundió de forma espectacular por todo el país.

El cultivo de la remolacha azucarera en España es un ejemplo de innovación que se introduce en el medio rural inducida desde ámbitos exteriores a él. Este carácter inducido se pondrá de manifiesto no sólo en las primeras ex- 
periencias innovadoras, sino también a lo largo del tiempo en su difusión por el territorio nacional. Difusión que se caracterizó por la rapidez e intensidad con que se llevó a cabo, debido a las eficaces estrategias que desplegaron los fabricantes de azúcar para potenciarlo y difundirlo, así como a la buena rentabilidad que este cultivo ha generado siempre a los agricultores, especialmente a los propietarios de pequeñas y medianas explotaciones agrarias, por más que en estos momentos se esté cuestionando, debido a lo reducido de los cupos de producción fijados por la PAC para nuestro país.

Analizamos a continuación cada una de estas experiencias y los efectos socio-económicos y territoriales de ellas derivados.

\section{La experiencia innovadora en la Vega de Granada. Primeros ensayos DEL CULTIVO DE LA REMOLACHA AZUCARERA}

En 1874 Juan López-Rubio Pérez, farmacéutico instalado en Granada, lleva a cabo los primeros ensayos en el cultivo de la remolacha azucarera en su cortijo de la Viña, ubicado en el término municipal de Cúllar-Vega, en plena vega granadina y muy próximo a la capital. Estos ensayos que se enmarcan en los ámbitos agrícola, genético, biológico, químico e industrial, sientan las bases para una rápida adopción del cultivo en toda la vega y en aquellas provincias andaluzas con tradición en la fabricación de azúcar a partir de la caña. LópezRubio mantiene a lo largo de los ensayos iniciales una relación muy estrecha con técnicos franceses que trabajaban en las fábricas de azúcar de caña de la costa granadina y malagueña y visita reiteradamente diversas fábricas de azúcar de remolacha de Francia y Alemania, países que contaban con los mayores adelantos técnicos en esta materia y en los que el cultivo de la remolacha y la fabricación de azúcar a partir de ella estaban dando magníficos resultados agro-industriales. López Rubio perseguía adoptar una innovación por imitación de un modelo espacialmente distante pero del que conocía su funcionamiento a la perfección, así como su elevada rentabilidad económica.

Una muestra de las remolachas obtenidas en 1874 fue enviada a Alemania para ser analizada en los laboratorios Skeiler, los más prestigiosos del país en análisis sobre química orgánica e ingeniería genética, con el fin de determinar su grado de riqueza en sacarosa. Los resultados fueron positivos, dando estas primeras remolachas cultivadas en España una riqueza en sacarosa similar a las cultivadas en Alemania, difiriendo sólo en un 10,5\%. Este hecho animó a López-Rubio a poner su experiencia en conocimiento de la Real Sociedad Económica de Amigos del País de Granada y solicitar su ayuda para poner en práctica el nuevo cultivo 
implicando a agricultores de la vega de Granada. La Real Sociedad Económica, conocedora de la crisis agraria por la que estaba pasando la vega y consciente de que la salida de la misma no podía efectuarse sin llevar a cabo una amplia gama de innovaciones, que contribuyeran a renovar y ampliar el número de cultivos y técnicas rentables, decide apoyar la iniciativa de López-Rubio, convirtiéndose así en el primer canal estimulador de la adopción del cultivo remolachero en España. En 1878 la Real Sociedad Económica repartió gratuitamente semillas certificadas de siete variedades de remolacha azucarera temprana entre los 152 empresarios agrícolas que se interesaron por el nuevo cultivo. Pertenecían a 49 municipios granadinos, de los cuales 31 eran de la vega de Granada y los restantes estaban localizados en distintos regadíos de la provincia (tabla 1 y figura 1).

Los primeros adoptantes eran en su mayoría propietarios de pequeñas explotaciones agrarias, que vieron en el nuevo cultivo una opción para salir del estado de crisis en que se hallaban desde hacía tiempo, pero también se encontraban entre ellos todos los grandes propietarios que posteriormente contribuirían a la consolidación de la industria azucarero-remolachera en nuestro país: Juan Ramón Lachica, Rodríguez Acosta, Juan Creus y el propio LópezRubio. Eran hombres con relevancia social y económica, que poseían explotaciones agrarias de gran tamaño y buscaban en el nuevo cultivo la materia prima necesaria para la creación de una industria que se perfilaba como altamente rentable. Algunos, como Lachica y Agreda, eran ya fabricantes de azúcar de caña y contaban con modernas instalaciones fabriles en Granada. Las expectativas que estos hombres tenían puestas en la fabricación de azúcar a partir de la remolacha se basaban en una serie de hechos perfectamente conocidos por intelectuales y hombres de negocios granadinos. A saber:

1) Las relaciones entre España y sus colonias antillanas, proveedoras de azúcar al mercado nacional, eran cada día más delicadas y se consideraba casi inminente la consolidación de la independencia de las mismas con respecto a la metrópoli.

2) El arancel sobre el azúcar antillano (de caña) y europeo (de remolacha) pesaba cada vez más sobre el precio que por el azúcar tenía que pagar el consumidor español.

3) La producción de caña peninsular no bastaba para cubrir más que un tercio del consumo nacional de azúcar y la superficie dedicada al cultivo de esta planta no podía ampliarse debido a sus exigencias climáticas, que no admite la más mínima helada.

4) Los resultados obtenidos en los países europeos en los que se obtenía azúcar de remolacha estaban siendo espectaculares, proporcionando a los fabricantes elevados beneficios económicos. 
5) El consumo de azúcar en el mercado interior aumentaba cada año, con lo que el Gobierno se veía en la necesidad de aumentar anualmente las importaciones de azúcar extranjero, lo que gravaba ostensiblemente la economía nacional.

TABLA 1

LOCALIDADES PIONERAS EN EL CULTIVO DE LA REMOLACHA AZUCARERA EN ESPAÑA Y NÚMERO DE ADOPTANTES (PROVINCIA DE GRANADA). AÑO 1878

\begin{tabular}{|c|c|c|c|}
\hline LOCALIDAD & $\begin{array}{c}\text { EXPLOTACIONES } \\
\text { ADOPTANTES }\end{array}$ & LOCALIDAD & $\begin{array}{c}\text { EXPLOTACIONES } \\
\text { ADOPTANTES }\end{array}$ \\
\hline Albolote & 2 & Huetor-Tajar & 1 \\
\hline Alcalá la Real & 1 & Huetor-Vega & 1 \\
\hline Alfacar & 1 & Huescar & 1 \\
\hline Alhama & 1 & Illora & 2 \\
\hline Alhendín & 2 & Ijar & 4 \\
\hline Ambros & 1 & Maracena & 3 \\
\hline Armilla & 3 & Monachil & 1 \\
\hline Aro & 1 & Motril & 2 \\
\hline Atarfe & 8 & Murchas & 1 \\
\hline Baza & 1 & Nigüelas & 2 \\
\hline Belicena & 2 & Nivar & 1 \\
\hline Benalúa de Guadix & 1 & Ojijares & 2 \\
\hline Caniles & 1 & Pinos Puente & 10 \\
\hline Fijuela & 1 & Padul & 1 \\
\hline Cullar-Vega & 6 & Pago de Aravenal & 2 \\
\hline Chauchina & 1 & Peligros & 2 \\
\hline Churriana & 1 & Pulianas & 2 \\
\hline Dílar & 2 & Purchil & 5 \\
\hline Dúrcal & 3 & Salar & 1 \\
\hline Faragüit Bajo & 1 & Santa Fe & 11 \\
\hline Fuente Vaqueros & 1 & Tablate & 1 \\
\hline Gojar & 2 & Tarramonta & 1 \\
\hline Granada & 30 & Viznar & 1 \\
\hline Guadix & 17 & Zubia & 3 \\
\hline Güevejar & 1 & & \\
\hline
\end{tabular}

Fuente: Informe dado por la Comisión nombrada por la Real Sociedad Económica de Amigos del País de la provincia de Granada sobre el cultivo de la remolacha azucarera en esta vega (1879). Archivo de la Facultad de Filosofía y Letras de la Universidad de Granada.

Elaboración propia. 
FIGURA 1

EXPLOTACIONES AGRARIAS PIONERAS EN EL CULTIVO DE LA REMOLACHA AZUCARERA EN ESPAÑA Y SU DISTRIBUCIÓN ESPACIAL EN LA PROVINCIA

DE GRANADA. AÑO 1878

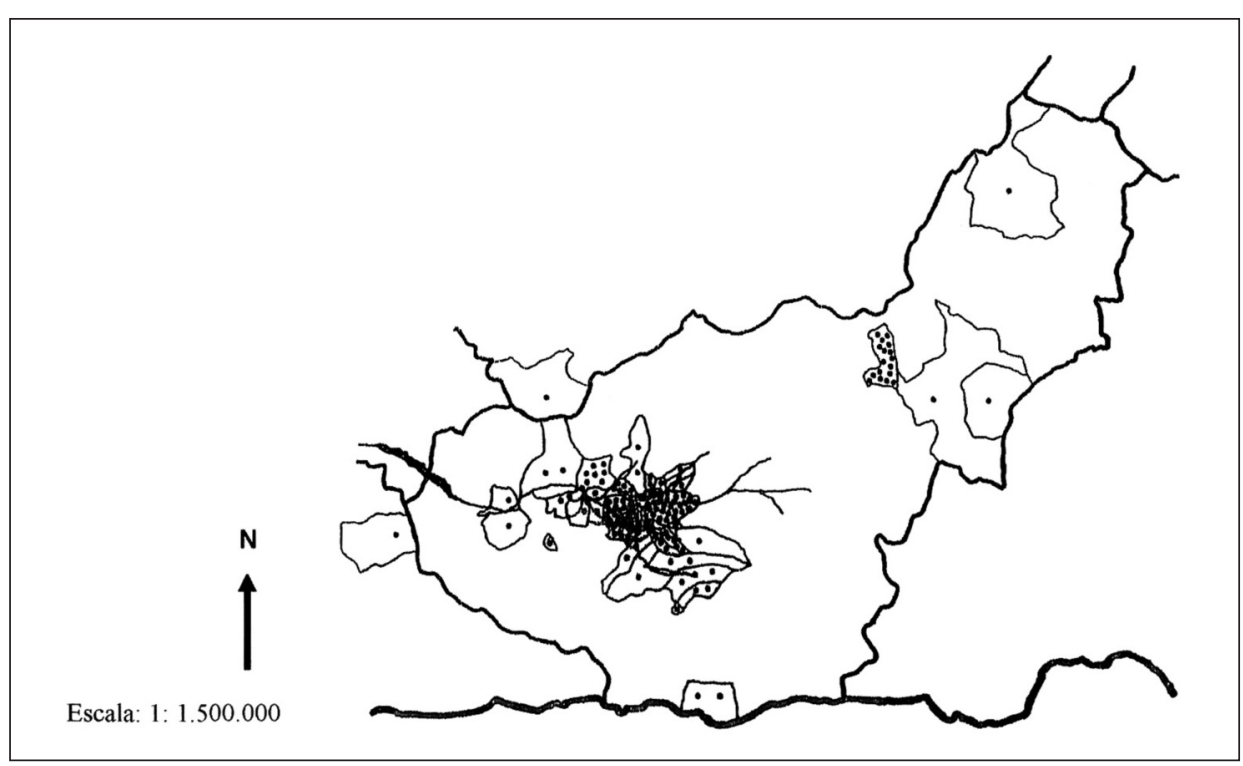

Fuente: Informe dado por la Comisión nombrada por la Real Sociedad Económica de Amigos del País en la provincia de Granada sobre el cultivo de la remolacha azucarera en esta vega (1879). Archivo de la Facultad de Filosofía y Letras de la Universidad de Granada. Elaboración propia.

En el mismo año de 1878 la Real Sociedad Económica de Amigos del País de Granada nombró una Comisión para el seguimiento del nuevo cultivo y el asesoramiento sobre el mismo a los adoptantes. Recogida la cosecha de 1878 se analizaron las remolachas obtenidas en tres laboratorios: el de de la compañía Fives Lille, de París, con amplia tradición en este tipo de análisis y en la fabricación de azúcar de remolacha; el de la Facultad de Ciencias de la Universidad de Madrid ${ }^{3}$ y el laboratorio que López-Rubio tenía en su farmacia de Granada. Los resultados alcanzados fueron considerados por la Comisión

${ }^{3}$ El Rector de la Universidad Central y profesor de la Facultad de Ciencias, Juan Creus, era uno de los hombre pioneros en el cultivo de la remolacha azucarera y en la fabricación de azúcar de remolacha, empresas que acometió asociándose con López-Rubio. 
tan positivos que el 12 de julio de 1879 emitió un informe en el que se aconsejaba la adopción del cultivo innovador con las siguientes palabras:

«Tanto por el producto principal, el azúcar, como por las consecuencias que del cultivo y su elaboración industrial se derivan, sería altamente ventajoso a la localidad adoptar el expresado cultivo, cuyos beneficios habían de ser tangibles colectiva e individualmente a no muy largo plazo» ${ }^{4}$.

Producto de estas actividades y de los sucesivos ensayos que sobre el cultivo se realizaron bajo la dirección de López-Rubio fue la creación, en noviembre de 1881, de la Sociedad Mercantil Creus y Rubio para «la creación y explotación de una fábrica de azúcar de remolacha y todas las demás operaciones anejas», con un capital social de un millón de reales, aportados al 50\% por Juan López-Rubio y Juan Creus como únicos accionistas. La fábrica, denominada «Ingenio de San Juan», fue equipada con la maquinaria y utillaje industrial más moderno del mercado, adquirido en Francia a la compañía Fives Lille. Estaba situada en el cortijo de «San Juan de Dios», a sólo cuatro kilómetros de la ciudad de Granada, en una finca acogida a la Ley de Colonias Agrícolas del 3 de julio de 1868, con la intención de aprovechar las ventajas fiscales que esta ley y las Órdenes Ministeriales del 15 de abril de 1879 y del 2 de marzo de 1874 concedían a los productos agrarios o industriales obtenidos en este tipo de explotaciones.

La primera campaña remolachero-azucarera realizada en el «Ingenio de San Juan» fue la de 1882-83, obteniéndose $66.000 \mathrm{~kg}$ de azúcar a partir de $1.329 \mathrm{t}$ de remolacha, de las cuales $571 \mathrm{t}$ fueron aportadas por los dos accionistas y el resto por los demás agricultores granadinos adoptantes del nuevo cultivo, a quienes se les pagó a 21,75 pesetas la tonelada, precio muy superior al de la media europea donde se pagaba la tonelada al equivalente de 17,25 pesetas. Con esta política de alto pago al agricultor los promotores del nuevo cultivo perseguían un objetivo muy claro: estimular a los agricultores hacia la adopción de un cultivo capaz de producir mayor rentabilidad económica a sus cultivadores que la generada por los cultivos tradicionales.

Los rendimientos de la primera campaña remolachero-azucarera fueron valorados como muy positivos, tanto por los promotores del nuevo cultivo como por los primeros agricultores adoptantes. Los altos rendimientos obteni-

${ }^{4}$ Informe dado por la Comisión nombrada por la Real Sociedad Económica de Amigos del País de la provincia de Granada sobre el cultivo de la remolacha azucarera en esta Vega y análisis practicado para la extracción de azúcar y alcohol. Aprobado y mandado imprimir y publicar en la Junta Central extraordinaria de 22 del 8 de 1879. Archivo de la Facultad de Filosofía y Letras de la Universidad de Granada. 
dos tanto en la cantidad como en la calidad de la remolacha cosechada, unido al alto precio que los agricultores percibieron por su producción, constituyen dos hechos decisivos para explicar la rapidez con la que el nuevo cultivo fue adoptado por numerosos agricultores en las siguientes campañas, la celeridad con la que se difundió por toda la vega de Granada y su inmediata difusión a distintas provincias andaluzas.

A estos dos hechos claves para estimular el proceso de adopción-difusión se sumó una nueva acción positiva llevada a cabo por López-Rubio. Éste, en su afán de favorecer la adopción del cultivo en las inmediaciones de su fábrica de azúcar, y siguiendo una costumbre ya consolidada en Europa, decidió establecer con los agricultores adoptantes acuerdos de producción a través de contratos de cultivo. En la campaña de 1884-85 se realizaron los primeros contratos de compra-venta de remolacha; en ellos se garantizaba a los agricultores la compra por parte de la fábrica de toda la remolacha cosechada, así como el precio a percibir por cada tonelada de remolacha entregada en fábrica. Por su parte, todo agricultor firmante de un contrato de cultivo se comprometía a entregar el número de toneladas de remolacha contratadas en cada campaña anual. Con este sistema de cultivo contractual se beneficiaban tanto los fabricantes como los agricultores, si bien las ventajas eran mayores para los primeros. El agricultor veía asegurada la venta de toda la remolacha cosechada y, al conocer el precio que percibiría por ella, podía hacer un cálculo real del valor de la producción, lo que le permitía planificar y programar el empleo del capital empresarial. El fabricante, por su parte, veía asegurada la provisión de materia prima necesaria para su fábrica y conocía el capital que necesitaba invertir para abastecerse de la misma independientemente de que la cosecha de la campaña fuera abundante o escasa.

Esta modalidad de cultivo contractual fue la que acabó imponiéndose en nuestro país, no sólo en los primeros momentos de la adopción del cultivo de la remolacha azucarera sino que se prolongará a través del tiempo hasta el momento actual, sin que las características fundamentales de los contratos de cultivo hayan sufrido modificaciones sustanciales.

Para terminar de vencer la inercia de los adoptantes potenciales, López-Rubio dio un paso más en su política de dar seguridad a los agricultores que optaran por el nuevo cultivo y decidió establecer en los contratos una cláusula por la que se concedía al agricultor contratante un anticipo en metálico sobre la cantidad de remolacha que se había comprometido a entregar en fábrica en cada campaña.

Con todos estos estímulos con los que contó el nuevo cultivo, tendentes a favorecer su adopción, no debe extrañarnos que tanto la superficie culti- 
vada con remolacha, como la producción de la misma aumentara de forma espectacular en las campañas inmediatas. Como ya hemos señalado, las explotaciones agrarias que la adoptan en la vega de Granada son numerosísimas. En la mayoría de los casos se trata de pequeñas explotaciones de carácter familiar, si bien algunas pertenecían a grandes terratenientes que vieron en el cultivo una excelente oportunidad para obtener beneficios. Así, de las 38 ha cultivadas en la campaña de 1882-83, con una producción de 1.329 t, se pasó, en sólo cinco campañas, a una superficie cultivada de 711 ha, con un volumen de producción de 32.000 t, llegándose en sólo diez años a las 3.000 ha y en 1900-01 a las 8.463 ha, con una producción de 253.879 t de remolacha. (tabla 2).

Así mismo, el número de fábricas de azúcar pasó de sólo una en 1882 a diez en 1891, ubicadas todas en la provincia de Granada (tabla 3), a excepción de la Azucarera Santa Isabel localizada en Alcolea (Córdoba) y propiedad de Torres-Cabrera, de cuya experiencia innovadora en relación con este cultivo trataremos en el apartado tercero de este artículo.

La ubicación espacial de estas fábricas se hizo con bastante racionalidad a pesar del escaso tiempo empleado en su planificación y la heterogeneidad de los capitales participantes en su creación. Cinco se localizaron en pleno regadío de la vega de Granada y muy próximas a la capital, a saber: Nuestra Sra. de las Angustias, San Cecilio, Señor de la Salud, La Bomba e Ingenio de San Juan; tres se ubicaron en dos municipios del NE de esta vega: San Fernando (Atarfe), Nuestra Sra. del Carmen y Nuestra Sra. del Rosario (Pinos Puente); una en Armilla, junto al río Dílar: Santa Juliana, y otra en el extremo occidental de la vega: Conde de Benalúa, en el municipio de Láchar (tabla 3).

En la campaña de 1892-93 se crean tres nuevas fábricas, esta vez en tierras malagueñas y almerienses, concretamente en Antequera (Azucarera Antequerana), Marbella (Azucarera de San Pedro de Alcántara) y Almería (Compañía Industrial Azucarera) (tabla 3). A partir de este momento el cultivo remolachero saltará a diversos puntos del agro peninsular de la mano de la industria azucarera, desencadenando un auténtico «boom» azucarero. Ya esta misma campaña de 1892-93 el cultivo salta a los regadíos del Ebro (Zaragoza, Casetas, Ariza) y a la provincia de Madrid (Aranjuez), donde se crean nuevas fábricas de azúcar de remolacha (tabla 3). Desde todos estos focos el cultivo remolachero se difundirá por todo el territorio peninsular hasta constituir uno de los cultivos más importantes del país, debido, no sólo al elevado volumen de terrenos agrarios que ocupa, sino también al importante número de explotaciones agrarias de carácter familiar que sustenta y a los elevados beneficios económicos que genera. 
TABLA 2

EVOLUCIÓN DE LA SUPERFICIE CULTIVADA Y DE LOS RENDIMIENTOS PRODUCIDOS POR EL CULTIVO DE LA REMOLACHA AZUCARERA EN LA

PROVINCIA DE GRANADA (1882-83 A 1900-01)

\begin{tabular}{cccc}
\hline $\begin{array}{c}\text { CAMPAÑ } \\
\left.{ }^{*}\right)\end{array}$ & $\begin{array}{c}\text { SUPERFICIE } \\
\text { CULTIVADA }(\mathrm{ha})\end{array}$ & $\begin{array}{c}\text { RENDIMIENTO } \\
(\mathrm{t} / \mathrm{ha})\end{array}$ & $\begin{array}{c}\text { PRODUCCIÓN } \\
(\mathrm{t})\end{array}$ \\
\hline $1882-83$ & 38 & 35 & 1.329 \\
$1883-84$ & 158 & 38 & 6.000 \\
$1884-85$ & 475 & 40 & 19.000 \\
$1885-86$ & 556 & 45 & 25.000 \\
$1886-87$ & 667 & 45 & 30.000 \\
$1887-88$ & 711 & 45 & 32.000 \\
$1888-89$ & 778 & 45 & 35.000 \\
$1889-90$ & 1.045 & 45 & 47.000 \\
$1890-91$ & 3.114 & 50 & 157.700 \\
$1891-92$ & 3.400 & 50 & 170.000 \\
$1892-93$ & 3.450 & 40 & 120.000 \\
$1893-94$ & 3.500 & 40 & 140.000 \\
$1894-95$ & 3.041 & 35 & 106.434 \\
$1895-96$ & 3.465 & 35 & 159.279 \\
$1896-97$ & 3.636 & 35 & 120.000 \\
$1897-98$ & 6.364 & 33 & 210.000 \\
$1898-99$ & 6.818 & 33 & 225.000 \\
$1899-00$ & 6.885 & 37 & 197.554 \\
$1900-01$ & 8.463 & 37 & 253.879 \\
\hline
\end{tabular}

Fuente: Boletines de Producción de Azúcares, Achicoria y Alcoholes. Dirección General de Aduanas.

Elaboración propia a partir de los datos correspondientes a las campañas analizadas.

${ }^{*}$ ) Las campañas de molturación se extienden habitualmente desde el mes de octubre hasta el mes de abril del año siguiente.

Especial atención se concedió desde los primeros momentos a la gestión de los medios de transporte de que dispondrían estas instalaciones, algunas de las cuales se ubicaron en puntos estratégicos desde este punto de vista. Téngase en cuenta que la cantidad de materia prima que moviliza la fabricación de azúcar es muy grande, de ahí la necesidad de que las fábricas estén situadas 
TABLA 3

PRIMERAS FÁBRICAS DE AZÚCAR DE REMOLACHA CONSTRUÍDAS EN ESPAÑA (1882-83 A 1892-93)

\begin{tabular}{|c|c|c|c|}
\hline FÁBRICA & UBICACIÓN & $\begin{array}{c}\text { INICIO DE } \\
\text { LA ACTIVIDAD }\end{array}$ & $\begin{array}{c}\text { POTENCIA } \\
(\text { Tm. remolacha / día })\end{array}$ \\
\hline Azucarera Santa Isabel & Alcolea (Córdoba) & $1882-83$ & 50 \\
\hline Ingenio de San Juan & Cullar-Vega (Granada) & " & 100 \\
\hline Ingenio de San Fernando & Atarfe (Granada) & $1884-85$ & 115 \\
\hline Ntra. Sra. de las Angustias & Granada & $1889-90$ & 200 \\
\hline Santa Juliana & Armilla (Granada) & 1891-92 & 500 \\
\hline Conde de Benalúa & Láchar (Granada) & " & 300 \\
\hline Señor de la Salud & Santa Fe (Granada) & " & 300 \\
\hline La Bomba & Granada & $"$ & 200 \\
\hline Ntra. Sra. del Rosario & Pinos Puente (Granada) & $"$ & 250 \\
\hline Nta. Sra. del Carmen & Pinos Puente (Granada) & $"$ & 120 \\
\hline San Cecilio & Granada & " & 200 \\
\hline Azucarera Antequerana & Antequera (Málaga) & $1892-93$ & 250 \\
\hline San Pedro de Alcántara & Marbella (Málaga) & " & 200 \\
\hline Cia. Industrial Azucarera & Almería & $"$ & 250 \\
\hline Azucarera de Aragón & Zaragoza & $"$ & 400 \\
\hline Azucarera de Aranjuez & Aranjuez (Madrid) & $"$ & 200 \\
\hline
\end{tabular}

Fuente: Boletines de Producción de Azúcares, Achicoria y Alcoholes. Dirección General de Aduanas. Elaboración propia a partir de los datos correspondientes a las campañas analizadas.

próximas a los campos de cultivo, así como de disponer de adecuados medios de transporte. Tres de estas primeras fábricas estaban situadas junto a la línea de ferrocarril Granada-Bobadilla (Ntra. Sra. del Carmen, Ntra. Sra. del Rosario y San Cecilio), mientras que las restantes, cuyos propietarios decidieron instalarlas en zonas de cultivo más alejadas de la capital granadina, quedaban a cierta distancia de las vías de comunicación existentes. Para solucionar esta situación, el Conde de Benalúa, cuya fábrica era la peor localizada en cuanto a las vías de comunicación, llevó a cabo la construcción de un ramal particular de ferrocarril desde Láchar, donde estaba su fábrica, hasta Illora, en la línea de Granada-Bobadilla para asegurarse el transporte de la remolacha necesaria para su fábrica. Las restantes fábricas proyectaron, mediante una acción conjunta, la construcción de una red de tranvías de mercancías a través de los cuales la remolacha llegaría a las fábricas. Pero este proyecto, después de varios fracasos, no llegó a consumarse y fue uno de los motivos fundamentales por los que estas fábricas con el paso del tiempo sucumbieron ante la compe- 
tencia de instalaciones mejor comunicadas y con mayores posibilidades de abaratar costos en el tratamiento industrial de la remolacha.

El rápido desarrollo de la industria azucarero-remolachera en la vega de Granada supuso una clara ventaja para el mundo agrario y de forma especial para los adoptantes del nuevo cultivo, que cada campaña eran más numerosos. La competencia entre los fabricantes que se disputaban la remolacha para mover sus fábricas, repercutió muy favorablemente en la difusión espacial del cultivo, ya que los agricultores adoptantes no quedaban a sujetos a la dependencia de un solo comprador, sino que formalizaban contratos de producción con el fabricante que les ofrecía mejores condiciones en aspectos tales como precio de compra de la remolacha, anticipos sobre la producción contratada, asesoramiento técnico, plazos de recepción de la cosecha ${ }^{5}$, etc., aspectos todos de suma importancia para reducir el factor riesgo a la hora de adoptar este nuevo cultivo.

Granada a través de esta experiencia, de enorme calado social, económico y territorial, constituye la comarca pionera en la adopción del cultivo de la remolacha azucarera en España, al tiempo que fue el principal centro difusor de esta innovación agraria e industrial, que en un corto periodo de tiempo cuajaría ampliamente en la agricultura nacional. Ya en la campaña de 1892-93 la remolacha se cultiva también en las provincias de Málaga, Almería, Zaragoza y Madrid, y en la primera década del siglo xx — tras la liquidación en 1898 de nuestro imperio colonial — la remolacha se difunde por el territorio nacional, ocupando importantes superficies agrícolas de numerosas provincias, alcanzándose altas cotas de producción a nivel nacional (tabla 4) Del mismo modo, las fábricas de azúcar de remolacha se multiplicaron con una velocidad vertiginosa, pasándose de las 10 fábricas de 1891 a 55 en 1910.

\section{LA EXPERIENCIA INNOVADORA EN EL REGADÍO CORDOBÉS Y LA PATENTE DEL PRIMER AZÚCAR DE REMOLACHA OBTENIDO EN ESPAÑA}

El veinticuatro de octubre de 1882 Ricardo Martel y Fernández de Córdoba, Conde de Torres-Cabrera, ofreció al rey Alfonso XIII «...las primicias de una industria, nueva en los dominios españoles: el azúcar de remolacha...»,

${ }^{5}$ La pérdida de sacarosa de las raíces después de cortadas, e incluso una vez pasado el momento óptimo de elaboración de sacarosa por parte de la raíz en el suelo, sigue siendo un problema en la actualidad, que enfrenta los intereses de cultivadores y fabricantes. Las soluciones arbitradas se basan en el establecimiento de plazos de entrega con carácter rotativo entre los agricultores de las áreas productoras. 
TABLA 4

EVOLUCIÓN DEL CULTIVO DE LA REMOLACHA AZUCARERA Y DE LA PRODUCCIÓN DE AZÚCAR DE REMOLACHA EN ESPAÑA (1882-83 A 1910-11)

\begin{tabular}{cccc}
\hline CAMPAÑA & $\begin{array}{c}\text { SUPERFICIE } \\
\text { CULTIVADA (ha) }\end{array}$ & $\begin{array}{c}\text { REMOLACHA } \\
\text { PRODUCIDA (t) }\end{array}$ & $\begin{array}{c}\text { AZÚCAR } \\
\text { PRODUCIDO (t) }\end{array}$ \\
\hline $1882-83$ & 38 & 1.329 & 72 \\
$1885-86$ & 556 & 25.000 & 8.296 \\
$1890-91$ & 3.114 & 157.700 & 39.426 \\
$1895-96$ & 3.465 & 159.279 & 41.115 \\
$1900-01$ & 8.463 & 253.879 & 63.825 \\
$1905-06$ & 13.530 & 678.048 & 72.910 \\
$1910-11$ & 22.312 & 966.685 & 86.146 \\
\hline
\end{tabular}

Fuente: Boletines de Producción de Azúcares, Achicoria y Alcoholes. Dirección General de Aduanas. Elaboración propia.

producida en su colonia agrícola de Santa Isabel, situada en Alcolea (Córdoba). A este azúcar le acompañaba una exhaustiva memoria en la que TorresCabrera recogía con gran riqueza de detalles el proceso seguido en la creación y organización de la colonia, los ensayos llevados a cabo para conseguir implantar en ella el cultivo de la remolacha azucarera y la creación dentro de esta colonia de la primera fábrica de azúcar de remolacha de España ${ }^{6}$. Este documento constituye una valiosísima fuente para el estudio de una de las dos experiencias pioneras llevadas a cabo en nuestro país sobre la adopción del cultivo remolachero y de la industria que de él se deriva. Además, pone de manifiesto la pugna que existió entre Torres-Cabrera y López-Rubio por conseguir la explotación en exclusiva de la naciente industria en nuestro país, temerosos ambos de que el Gobierno decidiera conceder el carácter de monopolio a esta actividad, al igual que se hacía en el resto de Europa. El capítulo relativo a patentes recoge los pleitos mantenidos por estos dos hombres para conseguir la patente en exclusiva para la instalación de sus fábricas de

${ }^{6}$ Martel y Fernández de Córdoba (1882) (facsímil de 1982): Introducción del cultivo y obtención del primer azúcar de remolacha en España, en la fábrica de la Colonia Santa Isabel de Alcolea (Córdoba). La edición facsímil fue patrocinada por la Universidad de Córdoba, la Asociación Nacional de Fabricantes de Azúcar y la Confederación Nacional de Cultivadores de Remolacha y caña azucareras, en homenaje a Torres-Cabrera con motivo del primer centenario de la fabricación del primer azúcar de remolacha en España. 
azúcar de remolacha. Pleitos que quemaron gran cantidad de ilusiones y energías de estos pioneros y que terminaron con la victoria de Torres-Cabrera primero que había presentado la solicitud de patente- que el 12 de junio de 1880 consiguió los derechos en exclusiva para fabricar azúcar de remolacha en España durante cinco años a partir de la adjudicación de la patente. Fabricación que inició en 1882 en la Azucarera Santa Isabel, instalada en la colonia agrícola del mismo nombre y primera de las creadas en nuestro país. Posteriores acuerdos entre Torres-Cabrera y López-Rubio permitieron al segundo levantar una fábrica remolachero-azucarera en Cullar-Vega (Granada), previa aceptación del pago al primero de un canon, correspondiente al 5\% de los beneficios anuales producidos durante cinco años. Los resultados no se hicieron esperar y en el mismo año en que Torres-Cabrera obtenía azúcar de remolacha en Santa Isabel, López-Rubio y su socio Juan Creus lo hacían en la azucarera creada por ellos en Cullar-Vega, como hemos expuesto en el apartado anterior.

Torres-Cabrera había logrado en 1882 su objetivo: ser el primer fabricante español de azúcar de remolacha legalmente reconocido. El camino que hubo de seguir para conseguirlo fue largo y cuajado de dificultades, pero su labor fue decisiva para el establecimiento de la industria azucarera-remolachera en España y para la adopción del cultivo remolachero en el ámbito agrario español. En 1872 dimitió como Gobernador Civil de Córdoba y se instaló con su familia en Alcolea (Córdoba), donde el 24 de octubre del año anterior había iniciado la creación de una colonia agrícola al amparo de la Ley de Colonización de 3 de junio de 1868. Esta ley, tendente a poblar el territorio español, a potenciar la creación de núcleos rurales y a estimular las actividades de la agricultura e industrias agrarias, concedía sustanciosas ventajas fiscales tanto a los terratenientes que fundaban colonias como a los colonos que se instalaban en ellas. Dos de estas ventajas eran de capital importancia para la empresa innovadora de Torres-Cabrera, como lo fueron para López-Rubio. Una, la exención que todos los productos de una colonia agrícola tenían del impuesto de consumo; otra, la exención del pago de aranceles en la importación de maquinaria destinada a cualquier fábrica enclavada en una colonia agraria y que manufacturara productos agrícolas o ganaderos. Debido a estos privilegios el azúcar que se obtuviera en estas colonias saldría al mercado a un precio más bajo que el obtenido por cualquier otro sistema de producción. Si a este hecho podía sumarse la obtención de la materia prima dentro de la propia colonia el ciclo quedaba perfectamente cubierto. Se hacía necesario, por tanto, investigar las posibilidades que había de introducir el cultivo de la remolacha azucarera, desconocido en España, en la colonia de Santa Isabel. 
Ahora bien, Torres-Cabrera había concebido un proyecto de colonia que transcendía las meras ventajas fiscales que la ley le concedía; buscando, además del propio beneficio, alcanzar mejoras sociales y económicas para el campesinado y contribuir con su acción innovadora al enriquecimiento del país. Estaba plenamente convencido - porque había estudiado concienzudamente los espectaculares resultados del cultivo remolachero en varios países europeos- de que la introducción de la remolacha azucarera como cultivo innovador, no sólo aseguraría a su colonia un próspero porvenir sino que a corto plazo sacaría a la agricultura española de la secular crisis en la que estaba sumida, al tiempo que potenciaría los sectores industrial, comercial y ganadero, con la consiguiente elevación del nivel económico del país. Entresacamos de la Memoria que envió a Alfonso XIII algunas frases que consideramos especialmente significativas de la empresa que se propuso llevar a cabo. En relación con la ayuda que se podía prestar a los campesinos que no poseían tierras, dice:

«... librar al colono de las garras de la usura y facilitarle los medios precisos para que pueda establecerse, conservar sus cosechas y esperar las naturales alzas del mercado para venderlas sin apuros y con estimación» ${ }^{7}$.

Sobre el nuevo cultivo y a su incidencia en la economía nacional expresa, entre otras reflexiones, lo siguiente:

«La remolacha sacarina era ... el cultivo más indicado para mi Colonia; pero ... mis colonos debían aprender a producirla en condiciones propias para la fabricación; yo debía comprarla y establecer en la Colonia una fábrica, primera de España, que fuera parte y complemento de aquella producción rural...; la explotación de esta preciosa raíz no sólo asegura el porvenir de la Colonia, sino que además debe también influir en el porvenir de nuestra agricultura, de nuestra industria y de nuestro comercio, aumentando el trabajo en el campo, acreciendo el valor de las tierras, multiplicando los centros manufactureros, facilitando con las hojas y con la pulpa el recrío de cerdos, el recebo de ganado vacuno, la lechería, la quesería, el plumón, el foigras, alimentando, en fin, millares de industrias secundarias» ${ }^{8}$.

Frases que, como demuestra el análisis que hemos realizado de su labor pionera, no pretendían falsear la realidad ni encubrir otras intenciones, ya que la intención de Torres-Cabrera fue siempre íntegra y si algún defecto se le puede achacar es, sin duda, el excesivo celo y tutela que ejerció sobre su colo-

\footnotetext{
${ }^{7}$ Martel y Fernández de Córdoba (1882).

8 Martel y Fernández de Córdoba (1882).
} 
nia, debido a la concepción paternalista que de la misma tenía. Palabras suyas son:

«... lo práctico es que la población rural sea el armonioso conjunto del propietario y el colono; que el dueño del suelo ofrezca al trabajador y a su familia los medios para establecerse en la finca y para trabajar en ella por cuenta propia, formando así la unidad tipo de la población rural; que esto lo haga en condiciones tan equitativas y recíprocamente beneficiosas, que ambos tengan interés en que siempre siga siendo así, y lo sostengan, sin necesidad de ningún contrato escrito»9.

«Mi Colonia no es otra cosa que el resultado práctico de la armonía más perfecta que he podido lograr entre el capital y el trabajo: la buena fe y la equidad, estrechando los lazos de afecto de los colonos entre sí y entre éstos y el propietario, forman de mi Colonia una sola familia...»10.

Los colonos podían vender los productos de sus cosechas individual o colectivamente de acuerdo con sus intereses y las condiciones del mercado. Un Banco Agrícola, con capital de Torres-Cabrera, concedía préstamos a bajo interés a los colonos cuando éstos tenían apuros económicos. Dos Jurados de Aguas, elegidos por los propios colonos, un Alcalde Pedáneo y un Consejo -formado por todos los padres de familia - formaban el conjunto de autoridades que velaban para que la justicia y la concordia reinaran en la colonia.

Torres-Cabrera no escatimó ni dedicación personal ni medios económicos para llevar a cabo su propósito de crear una colonia agrícola eficaz, en la que el objetivo fundamental sería cultivar remolacha para fabricar azúcar. Viajó repetidas veces a Francia y Alemania, países pioneros en el cultivo de la remolacha azucarera y en la elaboración de azúcar a partir de ella. Visitó gran número de fábricas y consultó a numerosos cultivadores y fabricantes franceses y alemanes sobre cuestiones agronómicas y de rendimiento industrial. Contrató los servicios de uno de los ingenieros más prestigiosos de los que entonces trabajaban en España: José María Martí, Director del Jardín Botánico de Valencia, y, bajo su asesoramiento, rectificó y mejoró los suelos de la colonia, realizó en ella costosas obras de regadío y ensayó todas las variedades conocidas de remolacha azucarera. En definitiva, puso todos los medios a su alcance para que el cultivo se adoptara y cuajara en el regadío cordobés. Cuando el proyecto innovador se puso en marcha todos los factores condicionantes se habían analizado concienzudamente. Nada en esta experiencia innovadora fue producto de la improvisación o del azar. Durante los primeros años de funcio-

\footnotetext{
${ }^{9}$ Martel y Fernández de Córdoba (1882).

10 Martel y Fernández de Córdoba (1882).
} 
namiento de la Colonia dominaron en ella los cultivos tradicionales, a los que se unió como cultivo innovador la remolacha azucarera, la cual se cultivó inicialmente en plan experimental, con el objetivo de convertirla en breve en el cultivo dominante en los terrenos de regadío de la Colonia.

La base territorial de la Colonia Santa Isabel la constituían 733 ha de suelos, en su mayor parte de baja calidad, ubicados en el término municipal de Alcolea, a $11 \mathrm{~km}$ de la ciudad de Córdoba, atravesados por la vía de ferrocarril de Madrid a Córdoba. En su extremo occidental la cruzaba el río Guadalquivir. En este marco territorial se llevó a cabo por primera vez el cultivo de la remolacha azucarera en España aunque, como hemos expuesto en el apartado anterior, López Rubio lo introducía de forma casi simultánea en la vega de Granada. Torres-Cabrera inicia los ensayos del nuevo cultivo en 1873. Tras repetidas experiencias, dirigidas personalmente por él, en 1878 decide repartir semillas de cuatro variedades de remolacha entre sus colonos. Éstos mostraron escasísimo interés por el nuevo cultivo, que creció sin las labores necesarias, sin abonos y con escasez de riego. En consecuencia, la cosecha obtenida fue muy baja y de mediocre calidad. A pesar de todo, Torres-Cabrera envió muestras de las remolachas cosechadas a las Estaciones Agronómicas de Madrid y Valencia para que fuera determinado el valor de las mismas desde el punto de vista industrial y se le asesorara sobre las necesidades agronómicas del nuevo cultivo en función de las características edafológicas y climáticas de sus tierras. Los informes emitidos por los dos laboratorios coincidieron en que la remolacha constituiría un cultivo altamente rentable en las tierras de la Colonia si se le practicaban las labores y cuidados adecuados. Según el informe de Madrid la producción media por hectárea podía fijarse en $46.000 \mathrm{~kg}$, que pagados a 50 céntimos el Qm., y deducidos los gastos de producción, proporcionaría al colono un beneficio medio de 1.500 reales por hectárea. Los análisis realizados en Valencia establecieron la producción potencial en $45.000 \mathrm{~kg}$ por hectárea, con un beneficio neto para el agricultor de 2.005 reales.

Un aspecto fundamental en el cultivo de la remolacha azucarera es la valoración de la riqueza en sacarosa cristalizable existente en las raíces, valor que condiciona su rentabilidad industrial. En este sentido, todas las remolachas analizadas alcanzaron un valor medio rentable, situado en una media de 9,7\%, excepto en el caso de la variedad globosa roja, cuyo cultivo fue desaconsejado. La comprobación de la rentabilidad industrial de las remolachas obtenidas a pesar del escaso interés mostrado por los colonos, llevó a Torres-Cabrera a contratar los servicios del anteriormente citado ingeniero agrónomo José María Martí. Con él recorrerá todos los países remolacheros de Europa, visitando las fábricas de azúcar y documentándose sobre el cultivo de la remolacha y las 
técnicas empleadas en las fábricas para su explotación industrial. Tras este periplo indagador, Martí se instala en Santa Isabel, dedicándose intensamente a la investigación experimental del cultivo con el objetivo de alcanzar raíces con el máximo posible de riqueza en sacarosa.

Los primeros ensayos científicamente controlados se realizan en la colonia en 1879, sobre una superficie de 3 ha, divididas en parcelas de 50 áreas cada una. Se eligieron tres tipos de suelos con características físicas y químicas diferentes, en los que se cultivaron dos variedades de remolacha. Los resultados alcanzados fueron muy positivos, alcanzándose una producción media de 30 Tm. por parcela. Así mismo, la riqueza en sacarosa de las remolachas obtenidas oscilaba entre el 14 y el 15\%, valor que superaba incluso al de las remolachas de otros países europeos, con valores medios del 13,5\%, a pesar de contar con mayor experiencia en el cultivo.

A partir de ese momento los estudios y experiencias sobre la remolacha se sucedieron en la Colonia sin interrupción. Durante cuatro años se estudiaron todas las variables condicionantes de la producción, se probaron múltiples tipos de abonos, los tiempos más adecuados para la siembra y la recolección, la distancia aconsejable entre las plantas, el número de riegos necesarios en consonancia con el clima y los suelos. Se ensayaron todas las variedades de remolacha existentes; e incluso, se trabajó con éxito en la consecución de semillas de calidad, con el fin de evitar el fuerte gasto que suponía la importación de semillas francesas o alemanas. Esta intensa actividad investigadora puso de manifiesto que la remolacha azucarera, a pesar de ser un cultivo muy exigente en suelos, abono, agua y mano de obra, compensaba con creces los gastos que ocasionaba, dejando un importante margen de beneficios al agricultor, que contrastaba con el beneficio generado por los cultivos tradicionales (tabla 5). El alto grado de exigencias de la remolacha llevó Martí a aconsejar su explotación como cultivo de alternancia trienal con cultivos tradicionales (patata, maíz, legumbres), sobre la base de que la remolacha sería el cultivo a mimar y acomodando el resto de los cultivos a las necesidades de ésta.

En 1881 se habían comprobado todos los factores condicionantes del cultivo remolachero y Torres-Cabrera considera llegado el momento apropiado para obtener en el laboratorio de la Colonia las primeras muestras de azúcar de remolacha producida en España. Torres-Cabrera, ante la calidad de este azúcar y animado por Martí, decide llevar a cabo la instalación de la tan anhelada fábrica de azúcar: la Azucarera Santa Isabel. Se cumplía así el objetivo durante tanto tiempo perseguido por este innovador, que, en su deseo de ser el introductor de la fabricación de azúcar de remolacha en España, se embarcó en una empresa agro-fabril capaza de aportar sabia nueva al agro español. 
TABLA 5

DIFERENCIA EN BENEFICIOS OBTENIDOS EN LA COLONIA STA. ISABEL AL CULTIVAR UNA HECTÁREA DE TERRENO DE REGADÍO CON CULTIVOS TRADICIONALES O CON REMOLACHA AZUCARERA COMO CULTIVO EXPERIMENTAL (1879)

\begin{tabular}{lccc}
\hline \multicolumn{1}{c}{ CULTIVO } & $\begin{array}{c}\text { GASTOS } \\
\text { (En ptas.) }\end{array}$ & $\begin{array}{c}\text { INGRESOS } \\
\text { (En ptas.) }\end{array}$ & $\begin{array}{c}\text { BENEFICIO } \\
\text { (En ptas.) }\end{array}$ \\
\hline Garbanzos & 28,00 & 122,00 & 94,00 \\
Patatas & 12,00 & 20,00 & 8,00 \\
Trigo & 23,00 & 184,00 & 161,00 \\
Maíz & 37,00 & 37,00 & 94,00 \\
Remolacha azucarera & 249,00 & 616,00 & 367,00 \\
\hline
\end{tabular}

Fuente: Martel y Fernández de Córdoba (1882): Introducción del cultivo y obtención del primer azúcar de remolacha en España en la Colonia Agrícola de Santa Isabel, de Alcolea (Córdoba). Edición facsímil de 1982. Elaboración propia.

La primera campaña de la Azucarera Santa Isabel se realizó en la primavera de 1882, lo que, como hemos señalado, permitió a Torres-Cabrera ofrecer a Alfonso XIII en diciembre de ese mismo año una muestra del primer azúcar de remolacha producido en España. En esta primera campaña se molturaron un millón ochocientos mil kilos de remolacha, con una producción de noventa y nueve mil kilos de azúcar y un beneficio del $47 \%$ sobre el capital invertido. La capacidad de producción de esta fábrica era reducida, ya que sólo contaba con una potencia capaz de molturar $50 \mathrm{tm}$. de remolacha. El deseo de su fundador fue precisamente éste, iniciar la experiencia pionera con una instalación «pequeña pero suficiente para el primer ensayo en España e irla ampliando en sucesivas campañas con los beneficios de su funcionamiento hasta hacer de ella una gran azucarera» (Martel y Fernández De Córdoba, 1882, 123).

Al beneficio económico que esta nueva industria proporcionaría a su creador en nuestro país, hay que unir el beneficio social que esta industria aportaría a la comarca mediante la generación de abundantes puestos de trabajo. Si tenemos en cuenta que esta pequeña fábrica ocupó en su primera campaña a ochenta y tres trabajadores, es lógico pensar que, con su ampliación y la creación de nuevas fábricas en la zona, el número de puestos de trabajo se incrementaría y se daría solución a uno de los problemas más graves del campo andaluz: el paro. Del mismo modo, la necesidad que las fábricas tendrían de abastecerse de remolacha como materia prima para su actividad industrial, 
aseguraría a los agricultores la venta de sus cosechas de remolacha, hecho que actuaría como estímulo para la adopción y difusión espacial del cultivo.

Sin embargo, el objetivo de hacer de esta primera fábrica una potente azucarera no llegó a cumplirse nunca, ya que las instalaciones de Santa Isabel no superaron nunca las $50 \mathrm{Tm}$. de potencia diaria. Tras los años inmediatos a su creación, en los que se elevó la producción inicial, siguieron años de decadencia (tabla 6) y, después de realizar una serie de campañas de escasa producción, fue aportada en 1903 al primer trusts azucarero creado en nuestro país: la Sociedad General Azucarera de España, que la mantuvo en funcionamiento hasta la campaña de 1910-11. Terminada esta campaña la S.G.A.E. procedió al cierre de esta fábrica, que era - cosa curiosa y a la vez triste- la azucarera con menos capacidad molturadora y la peor equipada de las existentes en ese momento en España.

Al declive de la que fue la primera fábrica de azúcar existente en España, se unió el retroceso y posterior desaparición del cultivo remolachero en tierras de la Colonia, único lugar de toda zona donde se había llevado a efecto, con lo que el nuevo cultivo, con tanta ilusión y esfuerzo introducido, desapareció totalmente de Córdoba. Y no se habría conocido en España de no ser porque en paralelo, y de forma totalmente ajena a la experiencia de Torres-Cabrera, otro innovador, José López-Rubio, estaba llevando a cabo una experiencia similar en la vega de Granada.

No existen fuentes que nos permitan comprobar si el cultivo desapareció porque los agricultores tuvieron dificultad para vender sus cosechas o, por el contrario, la azucarera cerró al encontrarse en una situación crítica por no contar con la materia prima necesaria para su funcionamiento. Ahora bien, debido al conocimiento que tenemos de la otra experiencia innovadora, realizada en Granada, así como del contexto en que se han enmarcado con posterioridad las relaciones entre cultivadores de remolacha y fabricantes de azúcar, nos inclinamos a pensar que fue la falta de estímulo por parte de la azucarera Santa Isabel lo que llevó a los agricultores a abandonar el recién adoptado cultivo. Sea cual fuere la causa, lo cierto es que a partir de 1906 la remolacha - que sólo había estado presente en Córdoba en la Colonia Santa Isabel- desaparece de tierras cordobesas, al tiempo que se difunde vertiginosamente por el territorio nacional. Habrá que esperar hasta 1934 para volver a encontrar este cultivo en el agro cordobés. En esta fecha se readoptará el cultivo de la remolacha bajo la acción estimuladora de la Azucarera San Rafael, ubicada en Villarrubia, la cual, bajo el sistema de contratos de cultivo, formalizó con los agricultores una cosecha de 361.938 Qm de remolacha sobre una superficie de 1.510 ha de regadío. 
TABLA 6

REMOLACHA MOLTURADA Y AZÚCAR PRODUCIDO EN LA AZUCARERA SANTA ISABEL (ALCOLEA-CÓRDOBA)

\begin{tabular}{ccc}
\hline CAMPAÑA & $\begin{array}{c}\text { REMOLACHA MOLTURADA } \\
(\mathrm{kg} / \text { día })\end{array}$ & $\begin{array}{c}\text { AZÚCAR OBTENIDA } \\
(\mathrm{kg} / \text { día })\end{array}$ \\
\hline $1882-83$ & 20.000 & 1.100 \\
$1885-86$ & 50.000 & 2.750 \\
$1890-91$ & 40.000 & 2.200 \\
$1895-96$ & 30.000 & 1.672 \\
$1900-01$ & 20.000 & 1.654 \\
$1905-06$ & 15.350 & 845 \\
$1910-11\left(^{*}\right)$ & 13.350 & 642 \\
\hline
\end{tabular}

(*) Última campaña en la que funcionó esta azucarera.

Fuente: Boletines de Producción de Azúcar. Asociación Nacional de Fabricantes de Azúcar (1920). Elaboración propia.

La vida de la azucarera Santa Isabel había terminado, pero la experiencia del innovador que la promovió, unida a la que paralelamente se llevó a cabo en la vega de Granada, sirvió para que el cultivo de la remolacha azucarera y la industria que de ella se deriva quedaran consolidados en España y constituyera el origen del que durante mucho tiempo ha sido un potente motor de la economía nacional; si bien, en la actualidad está en clara recesión debido, como hemos señalado anteriormente, al límite que sobre la producción de azúcar impone a nuestro país la Unión Europea a través del sistema de cupos a la producción.

\section{ANÁLISIS COMPARATIVO DE LAS DOS EXPERIENCIAS PIONERAS}

El análisis realizado de las dos experiencias pioneras que posibilitaron la aparición y adopción inicial de la remolacha azucarera como un cultivo nuevo en España, pone de manifiesto que existe entre ambas un claro contraste en cuanto a las repercusiones que tuvieron, tanto a nivel socioeconómico como en el marco territorial en el que se llevaron a cabo.

La experiencia innovadora de López-Rubio en la vega de Granada tuvo un amplio eco social, económico y paisajístico. Los agricultores de la comarca, influidos por la acción estimuladora de este hombre emprendedor, adoptaron 
con gran rapidez el nuevo cultivo, al que progresivamente fueron dedicando mayor cantidad de tierras y labores, lo que motivó que, desde los primeros años de la adopción, se produjera un aumento sustancial de los rendimientos por unidad de superficie. La remolacha ocupó grandes áreas de tierras irrigadas de las vegas de Granada, Guadix y Baza y en sólo once años su cultivo se difundió por las provincias de Granada, Málaga y Almería, saltando muy pronto a otras áreas del interior peninsular. En esta difusión jugaron un papel esencial las fábricas de azúcar, que, a través de la política de contratos de cultivo, fomentaron el interés de los agricultores por la remolacha azucarera y actuaron como auténticos catalizadores de este nuevo cultivo. Su introducción supuso una auténtica revolución agraria y socio-económica para los municipios adoptantes y, en general, para la economía nacional, que se pone de manifiesto a través de hechos concretos, entre los que cabe citar:

- Aparición de una potente industria agroalimentaria que emplea el nuevo cultivo para la obtención de azúcares y alcoholes.

- Configuración de una clase alta de comerciantes e industriales, que se enriquecieron con rapidez y facilidad por el elevado margen de beneficios generado por la remolacha y su tratamiento industrial.

- Solución del grave problema con el que se encontró España al perder en 1898 las últimas colonias ultramarinas, que tradicionalmente habían abastecido el mercado nacional con azúcar de caña.

- El número de puestos de trabajo aumentó drásticamente en la agricultura y en la industria. En la agricultura por el gran número de jornaleros que encontraron trabajo en las tierras de los latifundistas que desde el primer momento adoptaron el nuevo cultivo, así como por el elevado número de arrendamientos que se efectuaron para cultivar la nueva planta al amparo de los adelantos en efectivo y de las subvenciones que los fabricantes de azúcar concedieron a quienes se comprometieron, mediante contrato de cultivo, a producir cupos concretos de remolacha para la fábrica con la que habían suscrito el contrato. En el ámbito industrial la generación de puestos de trabajo fue también muy importante; la implantación de la nueva industria remolachero-azucarera supuso el reclutamiento de abundante mano de obra para poner en funcionamiento unas fábricas en las que, dado lo novedoso de esta industria, la mecanización era mínima y gran parte de las operaciones fabriles requerían el empleo de obreros y operarios.

- Fuerte expansión de las áreas irrigadas. El cultivo remolachero llevó aparejada la construcción de infraestructuras de regadío. Hemos de tener en 
cuenta que todas las variedades de remolacha que se introdujeron en España en los primeros momentos de la adopción del cultivo fueron variedades de regadío y de ciclo vegetativo corto.

- Cambio demográfico de las áreas adoptantes, que pasaron de ser zonas de emigración a ser zonas inmigratorias, debido a la gran cantidad de mano de obra necesaria para el cultivo remolachero y para el funcionamiento de las fábricas remolachero-azucareras.

- Los capitales generados por el cultivo remolachero y su explotación industrial convirtieron a las bancas modestas de Granada en instituciones financieras modernas y potentes.

- La riqueza generada por la remolacha y el azúcar de ella obtenida, también tuvo su reflejo en el urbanismo de los municipios adoptantes, que mejoraron sustancialmente su dotación en infraestructuras y edificaciones. En el caso de la ciudad de Granada, por ejemplo, la construcción del gran ensanche urbano de la ciudad mediante el trazado de la Gran Vía, coincide justamente con el periodo de esplendor económico que vivió la ciudad en el primer tercio del siglo xx como consecuencia de la actividad remolachero-azucarera. Por esta razón se la denominó «Gran Vía del Azúcar», denominación que siguen utilizando actualmente numerosos granadinos.

Por el contrario, a diferencia de la elevada repercusión que tuvo en Granada la iniciativa innovadora liderada por López-Rubio, la experiencia pionera puesta en marcha por Torres-Cabrera en el regadío cordobés tuvo muy escasa repercusión social, económica y territorial a nivel comarcal. A pesar del empeño y el tesón que este emprendedor puso en la acción innovadora, el cultivo de la remolacha azucarera no sobrepasó en Córdoba los límites de la Colonia Agrícola Santa Isabel, y la fábrica de azúcar de remolacha en ella creada no fue seguida de la creación de otras nuevas, hecho que si ocurrió, y de forma profusa, en Granada (tabla 3).

La explicación al rechazo de esta innovación en el área cordobesa hemos de buscarla en la conjunción de una serie de factores que actuaron sobre la misma de forma negativa, e impidieron que se pasara de la fase de adopción inicial a la fase de adopción generalizada y difusión de la innovación en el ámbito regional. El principal motivo fue, sin duda, la mentalidad con que TorresCabrera enfocó la introducción del nuevo cultivo y de la industria a él asociada. Asumió el proceso innovador de forma exclusivamente personal, sin buscar la colaboración de personas e instituciones que le ayudaran a extender la información sobre la innovación objeto de adopción y, en consecuencia, a 
lograr aumentar el número de adoptantes potenciales y el ámbito de influencia territorial de la innovación. A este hecho se unía la concepción paternalista que tenía de la empresa agrícola y de las relaciones entre el capital y el trabajo, que inhabilitaron a sus colonos para llevar a cabo una adopción del nuevo cultivo verdaderamente libre y decidida; por lo que, cuando faltó su dirección la experiencia se derrumbó y el nuevo cultivo fue abandonado sin haber cuajado de verdad.

A estas circunstancias, relativas a la personalidad del promotor de la innovación y de su enfoque de la empresa agro-industrial que acometió, se sumó un factor sumamente relevante en lo que a adopción de innovaciones se refiere. Nos referimos a la resistencia pasiva del campesinado cordobés, que carecía de una tradición agraria basada en la explotación de cultivos de regadío de carácter industrial, pues tradicionalmente en Córdoba se había practicado una agricultura de secano en las zonas de campiña y una agricultura basada en cultivos hortícolas de corte tradicional y sin innovaciones significativas en las vegas. Y, desde luego, en los grandes latifundios como en el que Torres-Cabrera ubicó la Colonia Agrícola Santa Isabel, nunca se había practicado una agricultura de carácter intensivo, sino que, por el contrario, se seguía dando una agricultura extensiva combinada con una rudimentaria utilización de las rastrojeras y los pastos naturales con ganado lanar y caprino.

Granada, por el contrario, contaba en su vega y en las de Guadix y Baza con una fuerte tradición hortícola en cultivos de consumo directo y de carácter industrial, dominando entre los últimos, de forma llamativa, la caña de azúcar, seguida en importancia por el cáñamo. La explotación de la tierra de forma intensiva era la tónica general en estas vegas, que contaban además con sistemas de irrigación muy avanzados.

La tradición cañera de la vega de Granada fue un factor que jugó de forma decisiva en favor de la experiencia innovadora liderada por López-Rubio, mientras que la falta de la misma lo hizo en detrimento de la experiencia cordobesa. En Córdoba nunca ha sido viable el cultivo de la caña de azúcar por razones de carácter climático; sin embargo, Granada contó con este cultivo y con industrias cañero-azucareras desde el siglo viII. Esta tradición azucarera llevó a muchos fabricantes de azúcar de caña a potenciar el cultivo de la remolacha como única alternativa a dos hechos claves: a) la imposibilidad física, por razones climáticas, de ampliar el número de hectáreas cultivadas con caña de azúcar y b) la pérdida, en 1898, de nuestras últimas colonias ultramarinas y con ella el cese del flujo de este producto antillano, que constituía hasta entonces la única materia prima para la fabricación de azúcar. Desde la Edad Media estuvo presente la industria cañero-azucarera en España, localizada 
exclusivamente en las costas del sur peninsular y los agricultores de estas áreas tenían conciencia de que las actividades vinculadas al cultivo de la caña y a su explotación industrial constituían negocios rentables. Este hecho tuvo una influencia psicológica altamente positiva en la adopción y difusión del cultivo remolachero en las provincias de Granada, Málaga y Almería. La remolacha se percibió como un cultivo nuevo que proporcionaría la materia prima necesaria a una industria que, aunque nueva, se vinculaba estrechamente con una actividad industrial tradicional y que generaba altos beneficios económicos y numerosos puestos de trabajo ${ }^{11}$. En Córdoba, por el contrario, se produjo una inercia psicológica que derivó en rechazo hacia un cultivo novedoso, cuya producción se destinaba a una industria sin raigambre en la zona.

La diferencia existente en el grado de aceptación de la innovación en las dos zonas donde originariamente se implantó, pone de manifiesto una ley que se cumple siempre en los procesos de adopción-difusión de innovaciones agrarias. Nos referimos al hecho de que cualquier innovación se adopta y difunde más rápidamente cuando guarda relación con otras actividades tradicionales, y por tanto ya conocidas en la zona en la que se pretende introducir, que si hace referencia a aspectos o actividades novedosos y totalmente desconectados con procesos de producción propios del entorno inmediato. El desconocimiento de la actividad económica que giraba en torno al azúcar y de los beneficios económicos que reportaba tanto a industriales como a agricultores, impidió a los potenciales adoptantes de la remolacha azucarera en Córdoba percibir las ventajas que esta innovación reportaría a la zona y a los propios agricultores y fabricantes. Esto les impidió reducir la valoración del riesgo que toda adopción de innovaciones lleva implícito y provocó el rechazo hacia la misma.

A este factor de componente psico-sociológico se une el grado de efectividad de las estrategias seguidas por los promotores de la innovación; es decir, por aquellos individuos o instituciones interesados en la implantación de la misma en un ámbito concreto. Los denominados propagandistas. En este sen-

${ }^{11}$ La caña dulce, originaria de Nueva Guinea, se difundió por las islas del Pacífico hasta llegar a la India, de donde fue traída a Europa por Alejandro Magno. Posteriormente, los árabes la difundieron por los países mediterráneos. En la época de esplendor del Califato de Córdoba se inicia en la vega de Granada el tratamiento de esta planta como cultivo industrial y se obtiene de ella el primer producto edulcorante cristalizado, al que se le da el nombre de azúcar. El cultivo se expande rápidamente por la vega granadina e inmediatamente llega a las costas malagueña y almeriense, constituyendo estas tres áreas la zona cañera de la península. Actualmente, tras el cierre en 2008 de la única fábrica de azúcar de caña que quedaba (ubicada en Salobreña, Granada), el cultivo de la caña de azúcar ha desaparecido de nuestro país. 
tido, como hemos visto a lo largo de este artículo las actuaciones de LópezRubio y de Torres-Cabrera fueron radicalmente diferentes. El primero buscó el apoyo de personalidades y entidades de reconocido prestigio entre los agricultores y creó una estrategia basada en dar seguridad a los adoptantes de la nueva planta - a través de la formalización de contratos de cultivo, concesión de anticipos en metálico, asesoramiento técnico, etc.—, sin mermar para nada su libertad en la toma de decisiones. Contrariamente, Torres-Cabrera actuó en todo momento a nivel personal y de forma aislada, sin buscar apoyo institucional ni crear ningún tipo de infraestructura sociológica que creara un clima favorable hacia la innovación y que facilitara la adopción de la misma por otros agricultores que no fueran sus colonos.

FIGURA 2

DIFUSIÓN ESPACIAL DEL CULTIVO DE LA REMOLACHA AZUCARERA EN ESPAÑA EN LOS INICIOS DE SU ADOPCIÓN

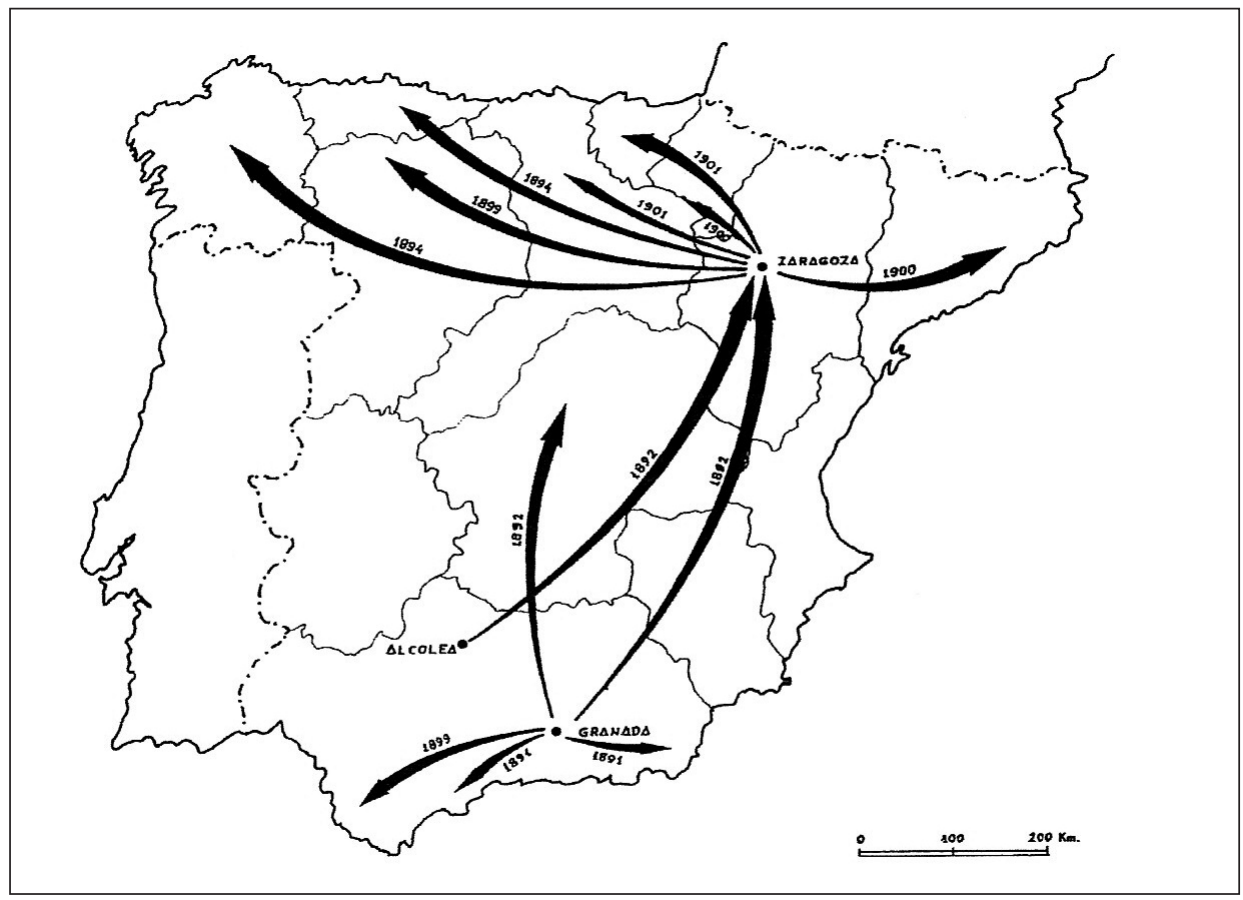

Fuente: Anuarios Estadísticos de la Producción Agraria. Ministerio de Agricultura. Elaboración propia.

Estudios Geográficos, Vol. LXXII, 270, pp. 103-134, enero-junio 2011

ISSN: 0014-1496, eISSN: 1988-8546, doi: 10.3989/estgeogr.201105 
Ahora bien, hay que destacar que, aunque la acción innovadora de TorresCabrera no tuvo continuidad en las tierras donde éste introdujo el cultivo remolachero, el conocimiento de que en su azucarera Santa Isabel se había obtenido el primer azúcar de remolacha de España fue clave para la creación de la industria azucarero-remolachera en nuestro país. A partir de su experiencia las fábricas de azúcar que empleaban esta materia prima se multiplicaron, al tiempo que el nuevo cultivo se difundió a regiones muy distantes de Andalucía, tales como Aragón, Castilla la Vieja, Galicia y Asturias (Figura 2), que iniciaron el cultivo de la remolacha azucarera por el conocimiento que tuvieron los industriales de estas áreas del nuevo azúcar de remolacha obtenida y patentada por Torres-Cabrera. La acción de las azucareras fue fundamental para la difusión del cultivo. Éstas, en su afán por asegurarse la materia prima para mover sus fábricas, arbitraron potentes medidas para inducir a los agricultores a adoptar el cultivo remolachero y para que este arraigara en las zonas receptoras. Esta tónica se ha mantenido en España a través del tiempo, hasta la actualidad.

Recibido : 13/07/2010

Aceptado: 10/12/2010

\section{BiBLIOGRAFÍA}

Asociación Nacional de Fabricantes de Azúcar (1920): Boletines de Producción de Azúcar. Madrid.

Baraja Rodríguez, E. (1994): La expansión de la industria azucarera y el cultivo remolachero del Duero en el contexto nacional. Madrid, Ministerio de Agricultura, Pesca y Alimentación, Serie Estudios, 82.

Marrón Gaite, M. J J. (2000): “Adopción de innovaciones agrarias y transformación de los espacios rurales. Variables condicionantes”, en VV.AA. Lecturas geográficas. Homenaje a José Estébanez Álvarez. Madrid, pp. 827-841.

Marrón Gaite, M. a J. (2004): "Adopción de innovaciones agrarias y desarrollo rural". En Marrón Gaite y García Fernández: Agricultura, Medio Ambiente y Sociedad. Madrid: Ministerio de Agricultura. Serie Estudios, pp. 133-152.

Martel y Fernández de Córdoba, R. (1882): Introducción del cultivo y obtención del primer azúcar de remolacha en España, en la fábrica de la Colonia Santa Isabel de Alcolea (Córdoba). Edición facsímil (1982), realizada por la Asociación Nacional de Fabricantes de Azúcar, la Confederación Nacional de Cultivadores de Remolacha y Caña Azucareras y la Universidad de Córdoba. 
Martín Rodríguez, M. (1982): Azúcar y descolonización. Origen y desenlace de una crisis agraria en la vega de Granada. Granada, Instituto de Desarrollo Regional de la Universidad de Granada.

Ministerio de Agricultura. Subdirección General de la Producción Agraria: Archivos sobre producción de remolacha azucarera en España. Madrid.

Ministerio de Fomento: Memorias relativas al cultivo de la remolacha azucarera. Madrid. (Periodo de 1892 a 1810)

Ministerio de Hacienda. Dirección General de Aduanas: Memorias sobre el estado de la Renta de Aduanas. Madrid. (Periodo de 1900 a 1914)

Ministerio de Hacienda: Resúmenes Estadísticos de los Impuestos sobre Alcoholes, Azúcares e industrias derivadas. Madrid. (Periodo 1890 a 1914).

Ministerio de Hacienda. Dirección General de Aduanas: Boletines de Producción de Azúcares, Achicoria y Alcoholes. (Periodo de 1882 a 1914).

Ministerio de Medioambiente y Medio Rural y Marino (2008): Anuario Estadístico de la Producción Agraria. Madrid:

Morell, L. (1888): Estudio sobre las causas de la decadencia de la agricultura en la provincia de Granada y medios para regenerarla. Granada: Real Sociedad Económica de Amigos del País.

Otero, J. y Rodríguez Ayuso, M. (1892): Memoria relativa al cultivo de la remolacha azucarera en la Granja Escuela Experimental de Zaragoza. Madrid, Ministerio de Fomento.

Palacio Atard, V. (1958): Primeras refinerías de azúcar en España. Madrid, Consejo Superior de Investigaciones Científicas.

Peña, F. (1964): El azúcar. Madrid, Banco Urquijo.

Real Sociedad Económica de Amigos del País de la Provincia de Granada (1879): Informe dado por la Comisión nombrada por la Real Sociedad Económica de Amigos del País de la provincia de Granada sobre el cultivo de la remolacha azucarera en esta Vega y análisis practicado para la extracción de azúcar y alcohol. Aprobado y mandado imprimir y publicar en la Junta Central extraordinaria de 22 del 8 de 1879. Granada, Archivo de la Facultad de Filosofía y letras de la Universidad de Granada.

Saillard, E. (1923): La remolacha y la fabricación de azúcar de remolacha. Barcelona: Salvat.

Soroa, J.M. (1934): Relaciones e influencias reciprocas entre el cultivo de la remolacha y la industria azucarera. Madrid, Ministerio de Agricultura.

Tortella, G. (1974): "El desarrollo de la industria azucarera y la guerra de Cuba". Moneda y Crédito, 91, pp. 65-139.

\section{RESUMEN}

En el presente artículo se investigan los inicios del proceso de adopción del cultivo de la remolacha azucarera en España, al ser introducida en nuestro país como innovación agraria a finales del siglo XIX. Un cultivo cuya adopción-difusión por el territorio nacional ha sido muy rápida desde sus orígenes y especialmente intensa a lo largo del tiempo, 
ocupando en la actualidad un papel claramente relevante en el panorama socioeconómico nacional, tanto por la superficie agraria que ocupa como por la riqueza que genera. Se analizan las dos experiencias pioneras llevadas a cabo en nuestro país, las cuales se realizaron de forma simultánea pero con independencia y desconocimiento la una de la otra y con enfoques socioeconómicos muy diferentes, en dos ámbitos espaciales muy próximos del agro andaluz: la vega de Granada y el regadío cordobés. Esta diferencia de enfoques condicionó decisivamente la influencia que cada una de ellas ejerció en los primeros momentos de la difusión del cultivo hacia otras zonas agrarias de nuestro país.

Palabras Clave: Innovación; adopción; difusión; remolacha azucarera; experiencias pioneras.

\section{Abstract}

The present paper studies the beginnings of the adoption process of the cultivation of sugar beet in Spain, to be introduced in our country as an agricultural innovation in the late nineteenth century. A culture whose adoption-diffusion through the national territory has been very fast since its inception and especially intense over the years, currently occupying a clearly relevant role in the national socio-economic scene, both by the agricultural area it occupies as by the wealth it generates.

We analyze the two pioneering experiences conducted in our country, which were carried out simultaneously but independently and with an ignorance of one another. They had a very different socio-economic approaches although they were conducted at two very close spaces in Andalusia: the fertile lowland of Granada and the irrigated land of Córdoba. This difference of approach decisively conditioned the influence each exerted in the early stages of the spread of farming to other agricultural areas of our country.

KEY WORDS: innovation; adoption; diffusion; sugar beet; pioneering experiences.

\section{RÉSUMÉ}

Cet article étudie les débuts du processus d'adoption de la culture de la betterave à sucre en Espagne, qui sera introduit dans notre pays et de l'innovation agricole dans la fin du XIXe siècle. Une culture dont l'adoption-diffusion à travers le territoire national a été très rapide depuis sa création et particulièrement intense au fil du temps, occuper un rôle aujourd'hui toute leur pertinence dans le paysage socio-économique national, tant par la surface agricole qu'il occupe comme richesses qu'elle engendre.

Nous analysons les deux expériences pionnières menées dans notre pays, qui ont été menées simultanément, mais indépendamment et l'ignorance les uns des autres et très différentes des approches socio-économiques de deux espaces très proche de l'agro andalouse: la plaine de Cordoue Grenade et l'irrigation. Cette différence d'approche résolument conditionné l'influence exercée chaque dans les premiers stades de la propagation de l'agriculture à d'autres régions agricoles de notre pays.

Mots CLÉs: l'innovation; l'adoption; la diffusion; la betterave à sucre; des expériences pionnières. 